\title{
Modelling of high temperature fatigue crack growth in Inconel 718 under hold time conditions
}

\author{
David Gustafsson, Erik Lundström and Kjell Simonsson
}

\section{Linköping University Post Print}

\section{Tweet}

N.B.: When citing this work, cite the original article.

Original Publication:

David Gustafsson, Erik Lundström and Kjell Simonsson, Modelling of high temperature fatigue crack growth in Inconel 718 under hold time conditions, 2013, International Journal of Fatigue, (52), 124-130.

http://dx.doi.org/10.1016/j.ijfatigue.2013.03.004

Copyright: Elsevier

http://www.elsevier.com/ 


\title{
Modelling of high temperature fatigue crack growth in Inconel 718 under hold time conditions
}

\author{
D. Gustafsson ${ }^{\mathrm{a}}$, E. Lundström ${ }^{\mathrm{a}}$, K. Simonsson ${ }^{\mathrm{a}}$ \\ ${ }^{a}$ Division of Solid Mechanics, Department of Management and Engineering, Linköping \\ University, SE-58183 Linköping, Sweden
}

\begin{abstract}
Inconel 718 is a frequently used material for gas turbine applications at temperatures up to $650^{\circ} \mathrm{C}$. The main load cycle for such components is typically defined by the start-up and shut-down of the engine. It generally includes hold times at high temperatures, which have been found to have a potential for greatly increasing the fatigue crack growth rate with respect to the number of load cycles. However, these effects may be totally or partly cancelled by other load features, such as overloads or blocks of continuous cyclic loading, and the actual crack propagation rate will therefore depend on the totality of features encompassed by the load cycle. It has previously been shown that the increased crack growth rate found in hold time experiments can be associated with a damage evolution, where the latter is not only responsible for the rapid intergranular crack propagation during the actual hold times, but also for the increased crack growth during the load reversals. In this paper, modelling of the hold time fatigue crack growth behaviour of Inconel 718 has been carried out, using the concept of a damaged zone as the basis for the treatment. With this conceptually simple and partly novel approach, it is shown that good agreement with experimental results can be found.
\end{abstract}

Email address: david.gustafsson@liu.se (D. Gustafsson) 
Keywords: nickel-base superalloys, fatigue crack propagation, Inconel 718, hold times, crack propagation modelling

\section{Introduction}

In gas turbines it is important to design for as high gas temperatures as possible in order to attain a high thermal efficiency [1]. For aeroengines, an increased temperature opens up for higher payloads, speed increase and greater range of operation. In the case of power generating gas turbines, the increase of temperature leads to lower fuel consumption, reduced pollution and thus lower costs [2]. The high-temperature load carrying ability of critical components is therefore one of the most important factors that set the limits in gas turbine design. Even though high temperature resistant superalloys are used, hot components are usually designed to run near their temperature and load limits. Uncertainties in models and methods used for fatigue life prediction under these circumstances are thus very problematic. Among the most important questions in gas turbine design today is therefore how to predict the life of such components.

Inconel 718 is a frequently used material for gas turbine applications at temperatures up to $650^{\circ} \mathrm{C}$. For such components, the main load cycle is typically defined by the start-up and shut-down of the engine. In this main loading cycle, hold times at high temperature are generally present for critical components. These high temperature hold times may greatly increase the fatigue crack growth rate with respect to the number of cycles, and it has been shown that this anomalous behaviour is due to material damage in the crack tip vicinity causing the material to fail by intergranular fracture [3-5]. Between these hold times different types of loadings can occur e.g. sections/blocks of continuous cyclic loading. These can be caused by abnormal service conditions but can also occur on a more regular basis due to e.g. different weather conditions and engine vibrations. It has been shown previously that not only the crack growth rate during the hold times but also the cyclic crack growth is affected by the 
material damage [6]. Thus, it becomes important to understand the interaction between hold times at high temperature and cyclic loading conditions in order to model the behaviour of e.g. real engine operation cycles.

Fatigue crack growth in Inconel 718 with high temperature hold times has been extensively studied previously, c.f. [4, 5, 7-13], which all show that hold times at high temperature may have devastating effects on the crack growth rate. The modelling of hold time effects is classically handled by additive models with a cyclic part, based on pure cyclic crack growth, and a time dependent part, based on pure time dependent crack growth, see e.g. [14-18]. However, this approach has been shown by e.g. Gustafsson et al. [6, 19] to be questionable from a physical point of view, see also [20]. When the crack growth during the hold time is separated from the crack growth occurring during the unloading and reloading, it was found that significant embrittlement of the grain boundaries has occurred [3]. This aspect was further discussed in [6] and [21] where it was concluded that not only the crack growth during the hold time but also the crack growth during load reversal was affected by the hold time period. Thus, a significant part of the cracking takes place during the unloading and reloading of the test specimen, see also [20]. These effects were also found in thermomechanical fatigue crack growth tests [22]. Furthermore, in [6] a study of the relative contributions of cyclic and time dependent crack growth was performed. It was shown that, for the load cycles considered, the cyclic part generally contributes more than the time dependent part for shorter hold times, while the opposite is the case for longer hold times.

When it comes to describing the time dependent behaviour, some authors use a simple phenomenological modelling approach, basically modifying the Paris law [23] by including parameters such as frequency and temperature to account for the time dependence of the high temperature crack growth process, see e.g. [13]. Others use a more physically based approach and their modelling is usually based on an observation of a specific crack growth or damage mechanism, such as oxide penetration see e.g. [25-29], and more recently [30] and [31]. 
Although a number of different models already exist for predicting fatigue crack growth in high temperature applications, only a few have dealt with transitions between blocks of hold times and blocks of cyclic crack growth, see e.g. [32] where Inconel 100 was investigated, and [33] where Inconel 718 was investigated and modelled using a linear cumulative damage model. In these papers the transients between hold time cycles and pure cyclic loading were investigated. This has also been studied in e.g. [6, 21] and [34] for Inconel 718 and Inconel 783, respectively. However, the specific modelling of the transient effects between hold times and cyclic loading is still not completely covered in the literature.

The high-temperature hold times give rise to an embrittlement that causes intergranular fracture. The mechanisms of the hold time effect influence a volume of material around the crack tip, here referred to as the damaged zone, which gets a lowered resistance to fatigue crack propagation compared to the unaffected material, see e.g. [6] and also [7, 20, 35-39] for further discussions on the mechanisms behind the hold time effect. Measurements of the length of the damaged zone by changing load cycle type, are discussed in [6] and [40], and it has been found that its length varies with respect to temperature and hold time but is usually, in a stabilized state, tenths of millimetres which is generally much larger than the plastic zone.

In this paper, modelling of the hold time fatigue crack growth behaviour of Inconel 718 in the time dependent region and at the temperature $550^{\circ} \mathrm{C}$ has been carried out by using the concept of a damaged zone, where scale factors depending on its length are used for accelerating both the cyclic and hold time parts. This approach of using the length of the damaged zone in combination with scaling factors has to the authors knowledge not previously been discussed in the literature. In addition to having a reasonably sound physical foundation, this modelling approach is also shown to give good results for the considered low-frequency conditions. 


\section{Material and experimental procedure}

\subsection{Material data}

The material used in this test series was, as mentioned previously, Inconel 718, a wrought polycrystalline nickel based superalloy with a high content of Fe and Cr. Its composition (in weight \%) is presented in Table 1. The material was delivered in the form of bars with a diameter of $25.4 \mathrm{~mm}$ and was solution annealed for $1 \mathrm{~h}$ at $945^{\circ} \mathrm{C}$, followed by ageing at two temperatures, $8 \mathrm{~h}$ at $718^{\circ} \mathrm{C}$ and $8 \mathrm{~h}$ at $621^{\circ} \mathrm{C}$ according to the AMS 5663 standard. The line intercept method was used to estimate the grain size to be approximately $10 \mu \mathrm{m}$, which is representative for fine-grained forged materials in gas turbine components, e.g. turbine discs.

Table 1: Composition of elements for Inconel 718

\begin{tabular}{lllllllll}
\hline Element & $\mathrm{Ni}$ & $\mathrm{Cr}$ & $\mathrm{Mo}$ & $\mathrm{Nb}$ & $\mathrm{Al}$ & $\mathrm{Ti}$ & $\mathrm{Fe}$ & $\mathrm{C}$ \\
\hline Weight\% & balance & 19.0 & 3.0 & 5.1 & 0.5 & 0.9 & 18.5 & 0.04 \\
\hline
\end{tabular}

\subsection{Experimental crack growth procedure}

Crack growth experiments were conducted on Kb-type specimens with rectangular cross sections of $4.3 \times 10.2 \mathrm{~mm}$, see Fig. 1. An initial starter notch of nominal depth $0.075 \mathrm{~mm}$ and total width of $0.15 \mathrm{~mm}$ was generated using electro discharge machining (EDM). Before the high temperature testing was carried out, the specimens were fatigue precracked at room temperature and $R=\sigma_{\min } / \sigma_{\max }=0.05$, to obtain a sharp semicircular crack with a depth of about $0.3 \mathrm{~mm}$. All tests where interrupted at an approximate crack length of 2.5 $\mathrm{mm}$. The fatigue crack growth testing was then carried out under load control using an MTS servo hydralic machine with a maximum load capacity of 160 $\mathrm{kN}$, using an Instron 8800 control system and the software WaveMaker. The furnace used was an MTS high temperature furnace with three temperature 
zones (model 652.01/MTS with a temperature controller of model 409.81). The crack propagation was monitored by the direct current Potential Drop (PD) technique according to ASTM E 647 [41] using a Matelect DCM-1, 2 channel pulsed DCPD system. The load at each hold time corresponded to $\sigma_{\text {hold }}=650$ MPa. Furthermore, all tests were done in laboratory air and at a load ratio of $R=\sigma_{\min } / \sigma_{\text {hold }}=0.05$.

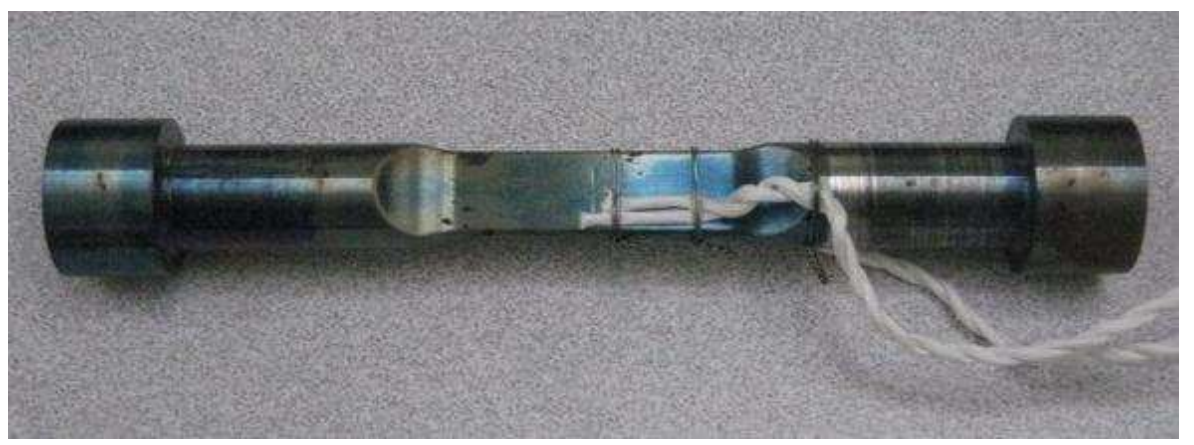

Figure 1: Instrumented Kb-type test specimen

The measured PD ratio was translated to crack length, assuming a semi-circular crack front, which was confirmed post-mortem, through an experimentally obtained calibration function based on initial and final crack lengths measured on the fracture surface as well as by measured induced beach marks. This method for monitoring the crack length has an accuracy of $0.01 \mathrm{~mm}$ crack length. Finally, the analytical solution for the stress intensity factor $K$ was obtained using a presolved case for a semi-elliptic surface crack [42]. For a detailed record of the material and experimental conditions we also refer to $[3,6,21]$.

\section{High temperature fatigue crack growth modelling; physical moti- vation, adopted modelling framework and parameter calibration procedure}

In this section the adopted modelling framework and its physical basis are presented and discussed. Furthermore, also the parameter calibration procedure is 
discussed from a conceptual point of view. Detailed calibration and validation results are found in Section 3.3.

\subsection{Physical motivation; damaged zone and crack driving mechanisms}

As discussed previously, it has been found that high-temperature hold times give rise to an embrittlement that causes intergranular fracture. However, it has also been shown that the ratio between transgranular and intergranular fracture depends on both temperature and hold time length [13]. Conceptually, three fracture type regions can be identified, representing i) fully cycle dependent transgranular fracture, ii) fully time dependent intergranular fracture and iii) mixed type transgranular and intergranular fracture, where the ranges of the latter become shorter for higher temperatures. Furthermore, it is to be noted that even for long hold times and/or high temperatures, mixed mode cracking can be dominant in transient regions when a damaged zone is not yet fully developed.

The underlying mechanisms of the hold time effect are still not fully understood. However, two dominating theories can be found: stress accelerated grain boundary oxidation and dynamic embrittlement [37], where the former process involves oxidation of grain boundaries ahead of the crack tip and subsequent cracking of the oxide, exposing new surfaces to oxygen. The dynamic embrittlement theory on the other hand advocates embrittling of the grain boundary by oxygen diffusion, separation of the embrittled boundaries and subsequent oxidation of the fresh surfaces $[7,35,38,43]$.

Whatever mechanism is active, the damaged zone itself is probably a volume of embrittled and partially cracked material, c.f. [6, 35, 36, 38, 39]. In these works it is shown that intergranular cracks grow in preferable grain boundaries which leads to an uneven crack front. Certain parts of the crack grow faster and unbroken microscopic ligaments are left behind the crack front, see e.g. $[6,36,43]$. 
In [19] it was shown that, for sufficiently long hold times, the crack driving mechanism acting in front of the crack fully controls the crack growth rate. Whenever a load reversal is applied, the main crack will propagate into material with lower crack growth resistance and, as long as the main crack does not propagate too far into the damaged zone, such a load reversal will not affect the overall crack growth rate per time increment $(\mathrm{d} a / \mathrm{d} t)$.

\subsection{Adopted modelling framework}

Based on the observations discussed in Section 3.1, it is obvious that to be able to model the correct crack growth behaviour in a high temperature hold time (HT) context it is imperative to be able to model the evolution of the damaged zone. Furthermore, since it has been shown in previous work that the damaged zone affects the crack growth of both the load reversals and the hold time part of the load cycle it becomes natural to use an additive description. Finally, since our modelling frame work is set up using the concept of a damaged zone as the foundation, its main domain of validity will be the time dependent region, see Section 3.1.

In detail the following additive law is proposed

$$
\left(\frac{\mathrm{d} a}{\mathrm{~d} N}\right)_{\text {total }}=\left(\frac{\mathrm{d} a}{\mathrm{~d} N}\right)_{\text {cyclic }}+\left(\frac{\mathrm{d} a}{\mathrm{~d} N}\right)_{\text {time dependent }}
$$

where

$$
\left(\frac{\mathrm{d} a}{\mathrm{~d} N}\right)_{\text {cyclic }}=S_{c}(D) \cdot\left(\frac{\mathrm{d} a}{\mathrm{~d} N}\right)_{\text {baseline }}=S_{c}(D) \cdot C_{c}(\Delta K)^{n_{c}}
$$

and

$$
\begin{aligned}
\left(\frac{\mathrm{d} a}{\mathrm{~d} N}\right)_{\text {time dependent }} & =\int_{t_{\text {hold }}} S_{t}(D) \cdot\left(\frac{\mathrm{d} a}{\mathrm{~d} t}\right)_{s} \mathrm{~d} t \\
& =\int_{t_{\text {hold }}} S_{t}(D) \cdot C_{t}\left(K_{\text {hold }}\right)^{n_{t}} \mathrm{~d} t
\end{aligned}
$$


where the labelling "c" and " $\mathrm{t}$ " refer to cyclic- and time-dependent quantities, respectively and where the label $s$ indicates stabilized time dependent crack growth. Furthermore, the labelling "baseline" refer to behaviour under standard testing, i.e. cyclic loading with a sufficiently large frequency for which no damaged zone has time to evolve. Finally, $S_{c}$ and $S_{t}$ are monotonically increasing scaling functions of the current length of the damaged zone $D$ and, finally, $C_{c}, n_{c}, C_{t}$ and $n_{t}$ are positive constants in the Paris law expressions.

It is to be noted that the use of a scaled baseline-term implicitly implies the assumption of sufficiently rapid load reversals. However, although the damaged zone is continuously growing during the hold times the crack is also growing, but usually at a much slower rate, see Fig. 2. Furthermore, if a block of cyclic loading should be imposed, the damaged zone would be progressively destroyed, see Fig. 3. Thus, the total rate of the evolution of the damaged zone will depend on two parts, $\dot{m}$ and $\dot{a}$, forming a combined rate where $\dot{m}$ represents the mechanism based growth rate of the damaged zone and $\dot{a}$ represents the crack growth rate. 

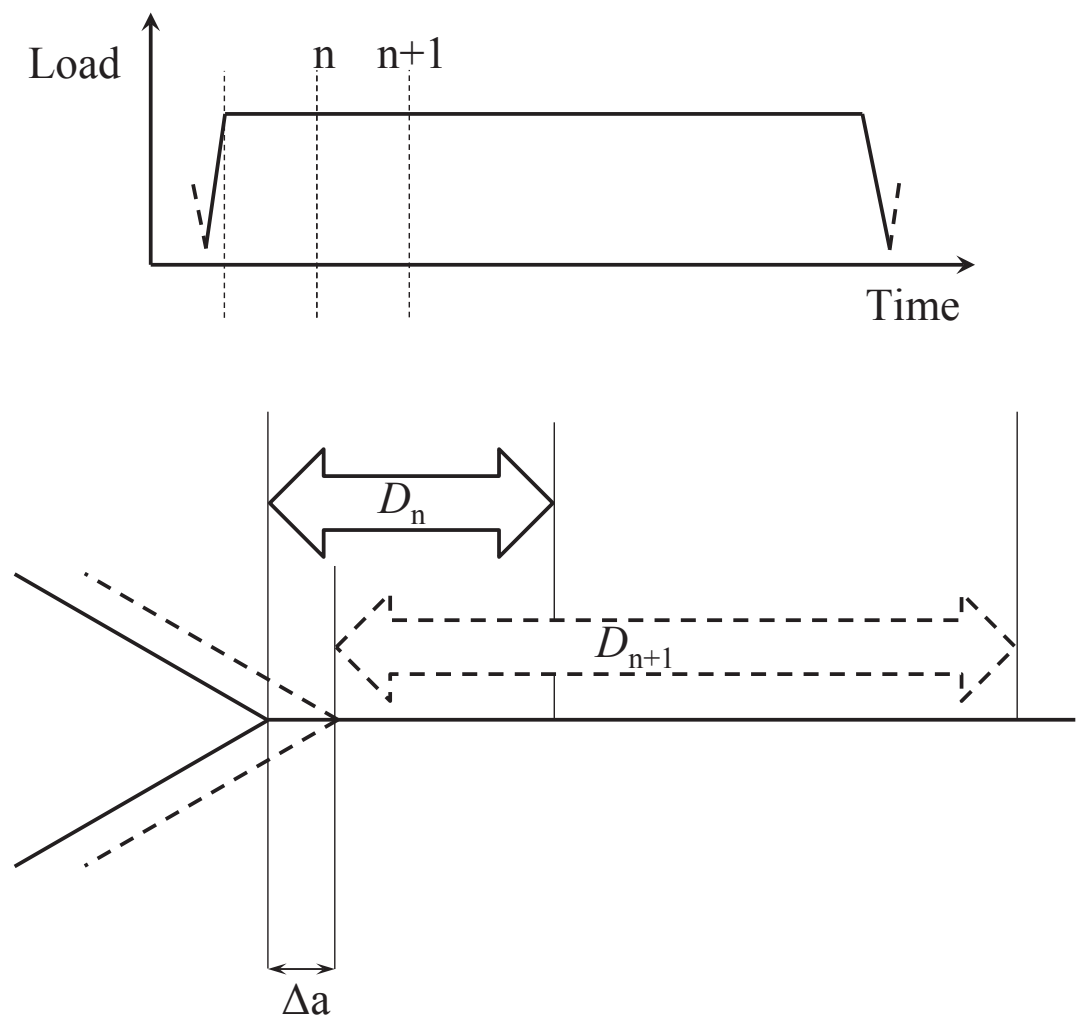

Figure 2: Build up of the damaged zone 


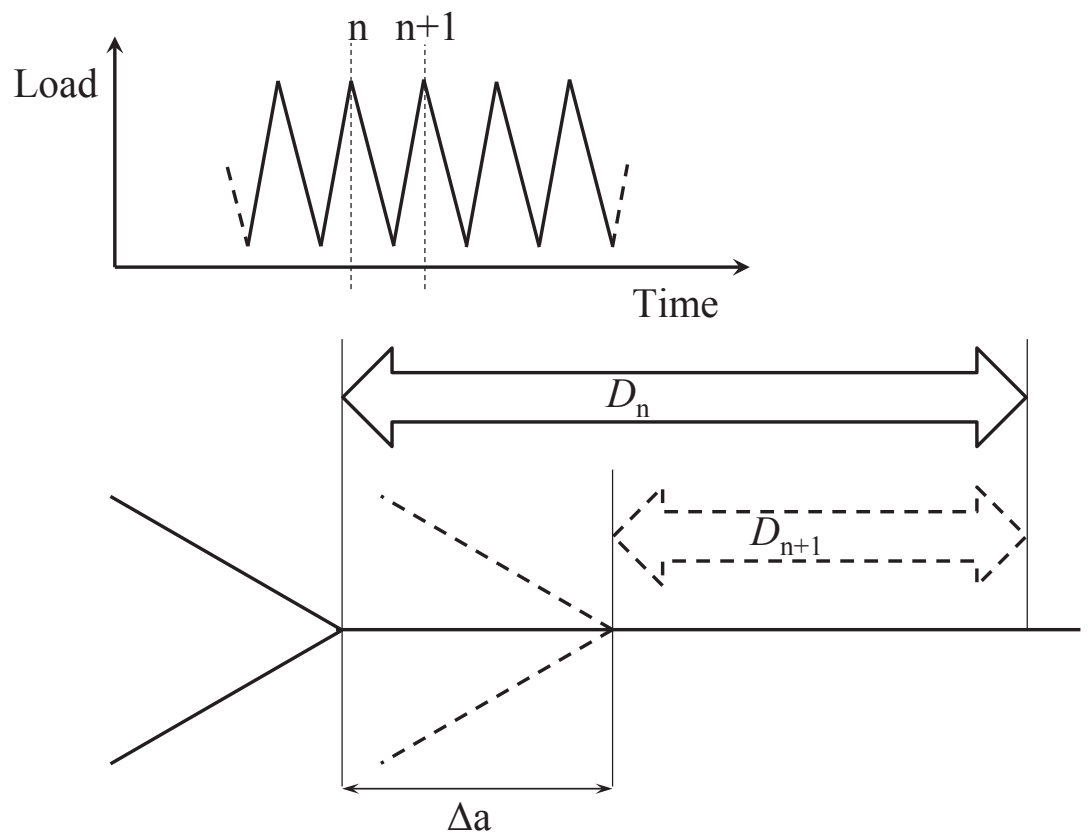

Figure 3: Destruction of the damaged zone

Based on the adopted time dependent crack propagation description, it is here proposed that

$$
\dot{D}=\dot{m}-\dot{a}
$$

$$
\dot{m}=C_{t} K_{\text {hold }}^{n_{t}}
$$

With this choice of evolution equation for $D$, in combination with the assumption of a monotonically increasing scaling function $S_{t}$, the evolution of $D$ will be stable in the sense that $D$ will never be larger than the value for which $S_{t}$ reaches unity. 
Since the frequency for the pure cyclic loading is assumed high, the mechanisms based crack growth during the load reversals can be neglected, thus implying

$$
\frac{\mathrm{d} D}{\mathrm{~d} N}=-\frac{\mathrm{d} a}{\mathrm{~d} N}
$$

Finally, the laws controlling $S_{t}$ and $S_{c}$ are to be set up. The first, $S_{t}$, controls to what extent the damaged zone affects the hold time part, see Eq. (7), and should e.g. be able to describe the transient from pure cyclic loading to a block of hold times, see Fig. 4.
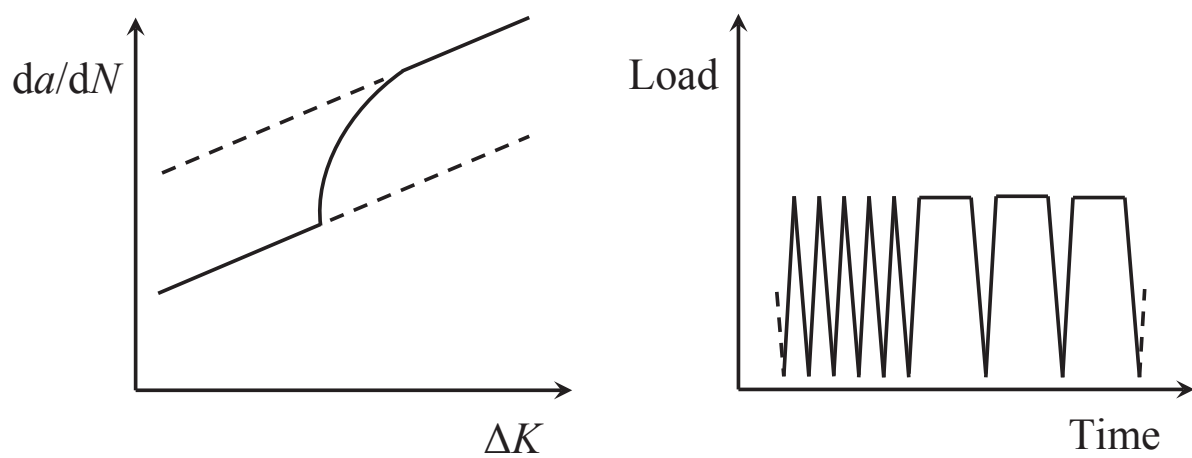

Figure 4: Acceleration of the fatigue crack growth with increased damaged zone length

Since $S_{t}$ is to be a monotonically increasing function of $\mathrm{D}$, and since it for the case of no damaged zone should be zero, it may be given the form found in Eq. (7) below, where $B_{t}$ is a fitting parameter

$$
S_{t}=\left(\frac{D}{D_{\max }}\right)^{B_{t}} \quad B_{t} \geq 0
$$

More complex expressions involving more parameters are of course possible to conceive, but in order to keep the description as simple as possible, and in order to introduce as few parameters as possible, the above expression was 
chosen. Note that the quantity $D_{\max }$ corresponds to the measurable length of the damaged zone under stabilized time dependent crack growth.

The second factor, $S_{c}$, controls to what extent the damaged zone influences the cyclic part, and should e.g. be able to describe the transient from a hold time block to pure cyclic loading, see Fig. 5 .
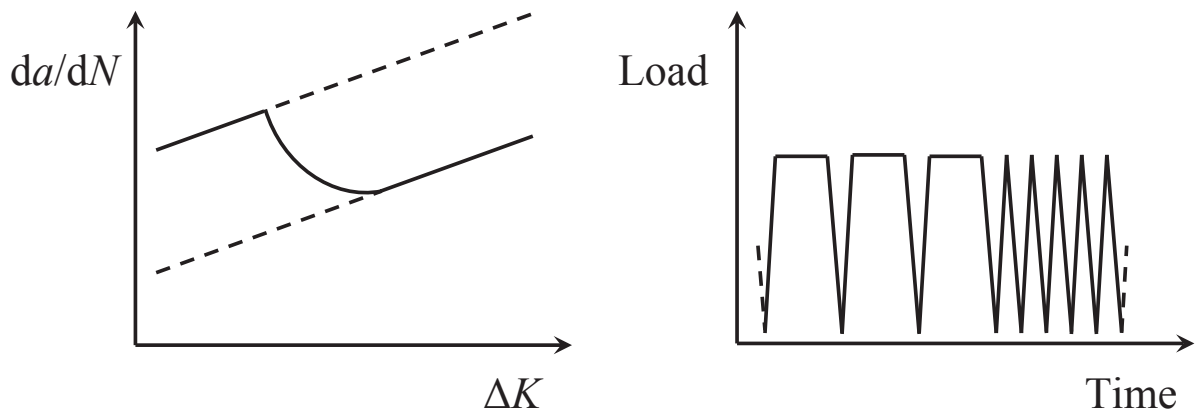

Figure 5: Deceleration of the fatigue crack growth due to reduced damaged zone

Since $S_{c}$ is to be a monotonically increasing function of $D$, and since it is to take the value one for the case of an "undamaged" crack-tip material, it may be given the form shown in Eq. (8), where the two fitting parameters $A_{c}$ and $B_{c}$ have been introduced

$$
S_{c}=1+A_{c}\left(\frac{D}{D_{\max }}\right)^{B_{c}} \quad B_{c} \geq 0
$$

Again, the simplest possible expression has been chosen in order to keep the model as simple as possible.

With the chosen evolution laws for $S_{c}$ and $S_{t}$, all crack growth rates will be between the pure cyclic fatigue crack growth rate and the pure time dependent crack growth rate. As one can see from the model expression in Eq. (7), $S_{t}$ will only reach its maximum value of one for sufficiently long hold times, which corresponds to pure time dependent crack growth, i.e. $D=D_{\max }$. The opposite 
applies for $S_{c}$, starting at a high value depending on how close $D$ is to $D_{\max }$, and slowly decreasing towards its minimum value of one as the damaged zone is completely "consumed". Thus, our model is robust in the sense that it will only predict crack growth within two well defined and classically well-known rates.

\subsection{Parameter calibration procedure}

The proposed model contains a small set of fitting parameters which can be found from basic experiments. Actually, as will be discussed in the last section below, all parameters can be determined from one single test type.

In this work, two types of tests have been used in the parameter calibration procedure; a pure time dependent crack growth test and a block test with hold times of $2160 \mathrm{~s}$. All tests were performed at $550^{\circ} \mathrm{C}$. In the block tests cyclic and hold time loadings were alternated in separate blocks. In detail, they start with a cyclic loading (without hold time) up to a specific crack length, then hold time crack growth periods up to a specific crack length and then both of these steps again, thus ending with a hold time crack growth period, see Fig. 6. Furthermore, each of these four blocks are run over an equal amount of crack length. It may be noted that such block tests were also used in $[6,21]$ to determine the length of the damaged zone for different hold times.

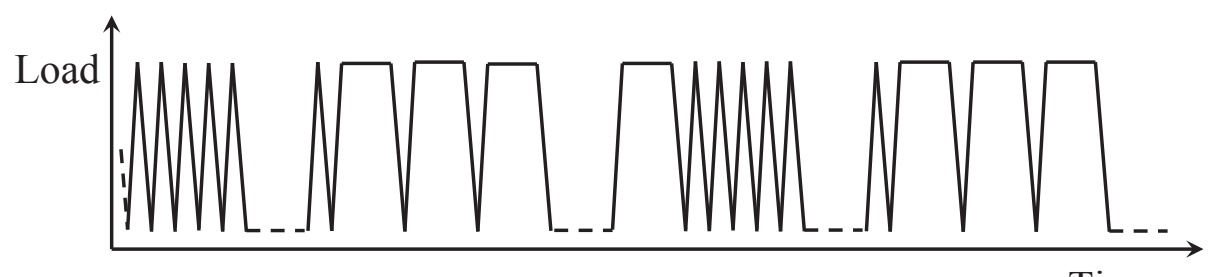

Time

Figure 6: Block test load curve 


\section{Results and discussion}

In this section the proposed model is calibrated and validated against previously reported experimental results $[3,6,19,21]$. The model has been implemented in MATLAB [44] and FORTRAN and an Euler Forward algorithm has been used to solve the crack propagation equations. Finally, the optimisation of the model parameters was done by using the commersial software LS-OPT [45], by minimisation of a least square based error function.

\subsection{Calibration}

The pure time dependent crack growth test is used to determine the parameters $B_{t}, C_{t}$ and $n_{t}$, where the last two are found from the stabilised part of the curve i.e. when the transition zone has ended. The values were found to be $5.76 \cdot 10^{-12}$ and 4.57 , respectively. The remaining parameter for the test, $B_{t}$, is optimised to fit the transient at the beginning of the test, see Fig. 7, and was found to be 1.62 . The stabilised damaged zone length, $D_{\max }$ was estimated to $0.5 \mathrm{~mm}$ based on the observations found in [21].

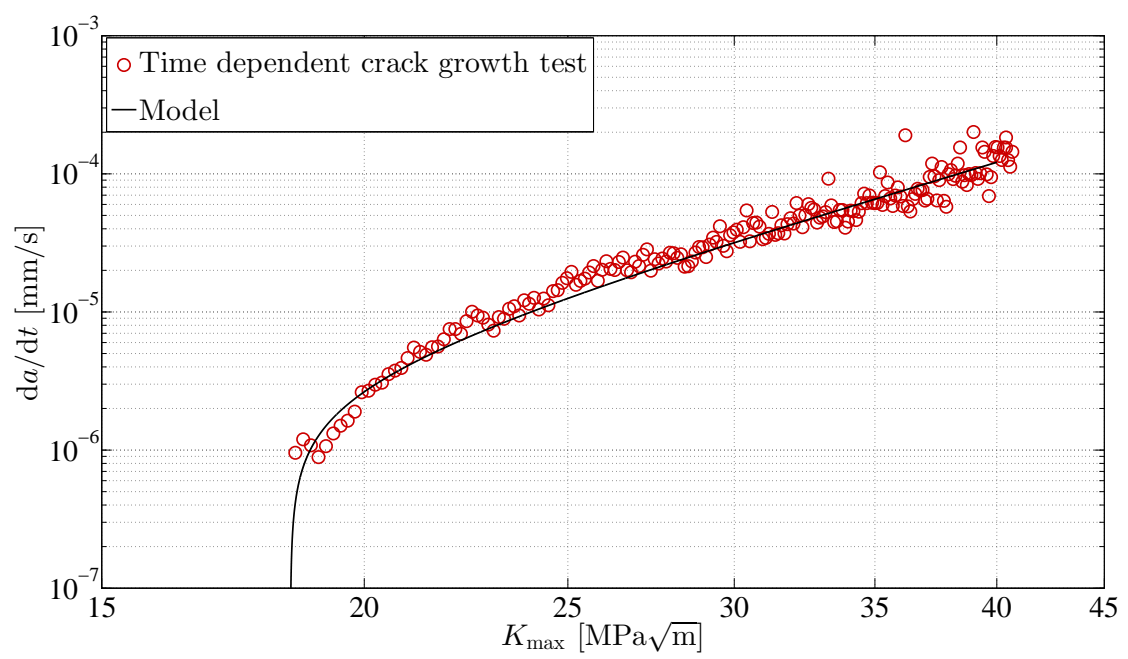

Figure 7: Parameter determination of $C_{t}, n_{t}$ and $B_{t}$ 
The block test is used to determine all remaining parameters in the cyclic part of the additive law. To start with, $C_{c}$ and $n_{c}$ are directly taken from the first cyclic part of the test and were found to be $1.26 \cdot 10^{-7}$ and 2.39 , respectively. The parameters $A_{c}$ and $B_{c}$ in $S_{c}$ were optimised to fit the first transient between hold time loading to cyclic loading, see Fig. 8, and were found to be 823 and 2.92 , respectively.

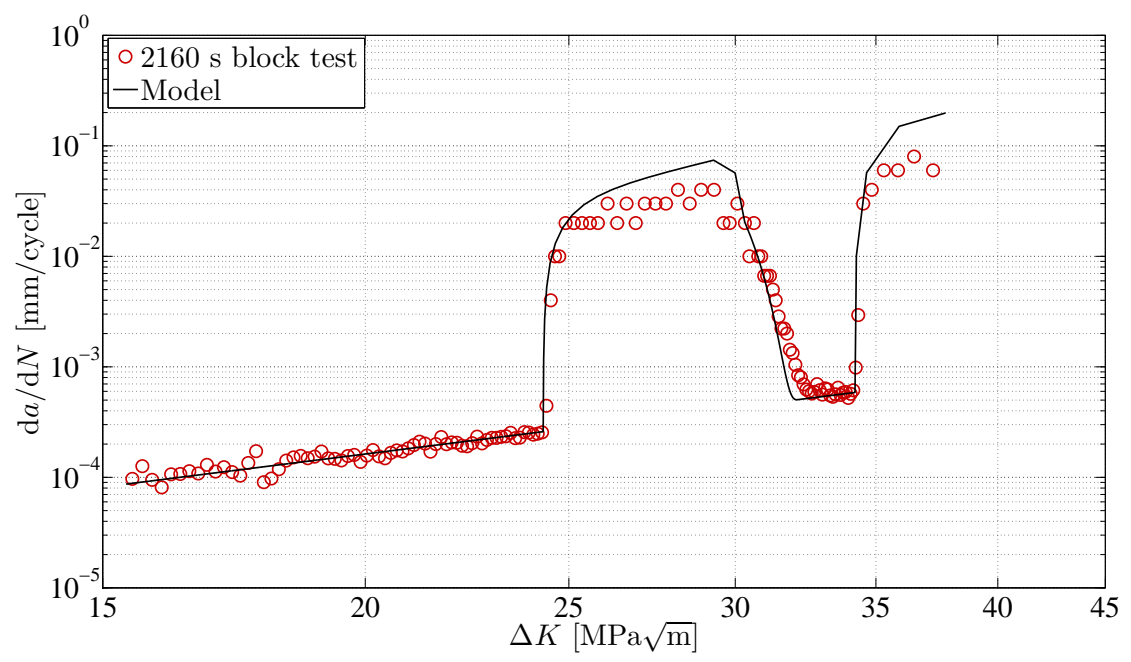

Figure 8: Parameter determination of $C_{c}, n_{c}, A_{c}$ and $B_{c}$

A summary of all material parameters is shown in Table 2 below.

\begin{tabular}{ll}
$\begin{array}{l}\text { Table 2: Optimised model paramete } \\
\text { Parameter }\end{array}$ & Value \\
\hline$C_{t}$ & $5.76 \cdot 10^{-12}$ \\
$n_{t}$ & 4.57 \\
$C_{c}$ & $1.26 \cdot 10^{-7}$ \\
$n_{c}$ & 2.39 \\
$B_{t}$ & 1.62 \\
$A_{c}$ & 823 \\
$B_{c}$ & 2.92 \\
\hline
\end{tabular}




\subsection{Validation}

The model was validated for five different tests, see Table 3. For a complete description of these tests see [3, 6, 19, 21].

Table 3: Tests used for model validation

\begin{tabular}{ll} 
Hold time $[\mathrm{s}]$ & Cycle type \\
\hline 2160 & Hold time test \\
21600 & Hold time test \\
21600 & Block test \\
90 & Block test \\
- & Long pre-crack time dependent crack growth \\
\hline
\end{tabular}

As can be seen in Fig. 9 the $2160 \mathrm{~s}$ and $21600 \mathrm{~s}$ hold time tests are captured reasonably well.

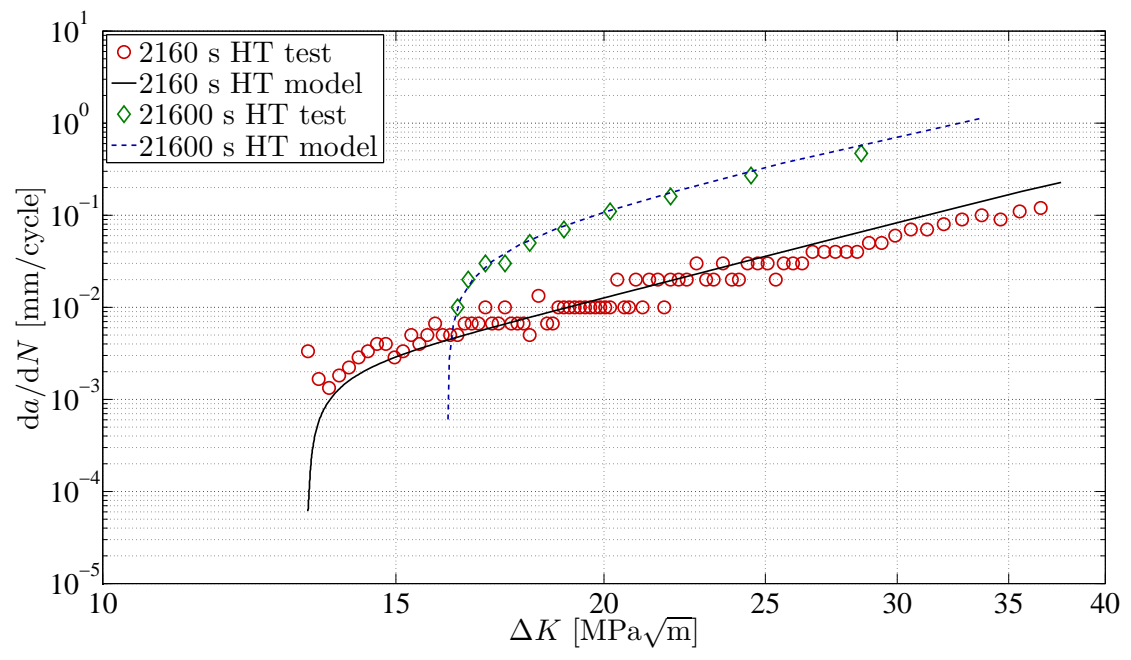

Figure 9: Model vs hold time tests

As an example of the model output for crack length vs. time, the result for the $21600 \mathrm{~s}$ hold time test is shown in Fig. 10. As can be seen the model captures 
the overall behaviour of the test satisfactorily. However, in this context the results for the $2160 \mathrm{~s}$ hold time test is not captured well, which is due to the very small initial transient found in that test. The reason for this is not clear, but is likely to be associated with the heating of the furnace after the initial pre-crack growth.

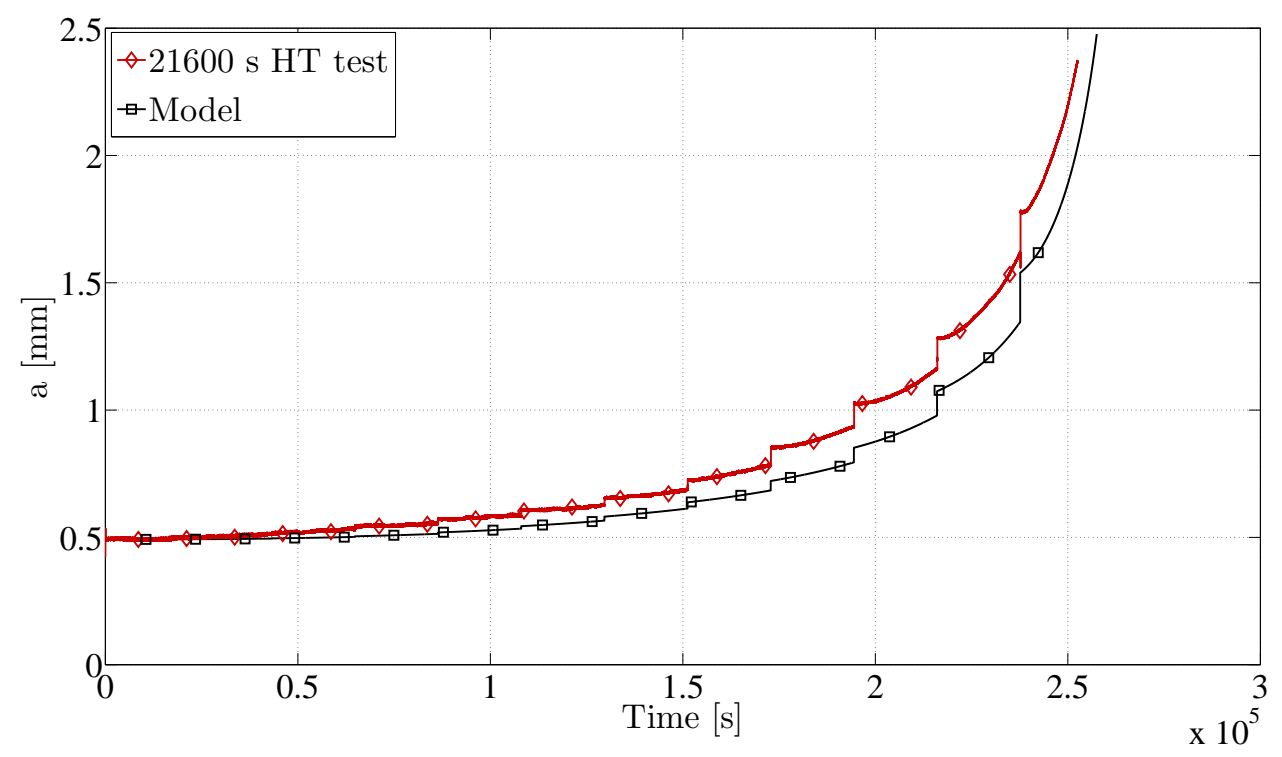

Figure 10: Crack length vs time for the $21600 \mathrm{~s}$ hold time test

In Fig. 11 a comparison between block test results with $21600 \mathrm{~s}$ hold time is shown. As can be seen, the transitions between blocks of hold times and pure cyclic loading are captured reasonably well. However, it is to be noted that the model predicts crack length as a function of time. To obtain results in a $\mathrm{d} a / \mathrm{d} N$ context, for the hold time cycles, the evaluation is based on the mean value of the crack length for each cycle. Thus, this explains why it seems that there is a part missing between the end of the first hold time block and the start of the second cyclic block. 


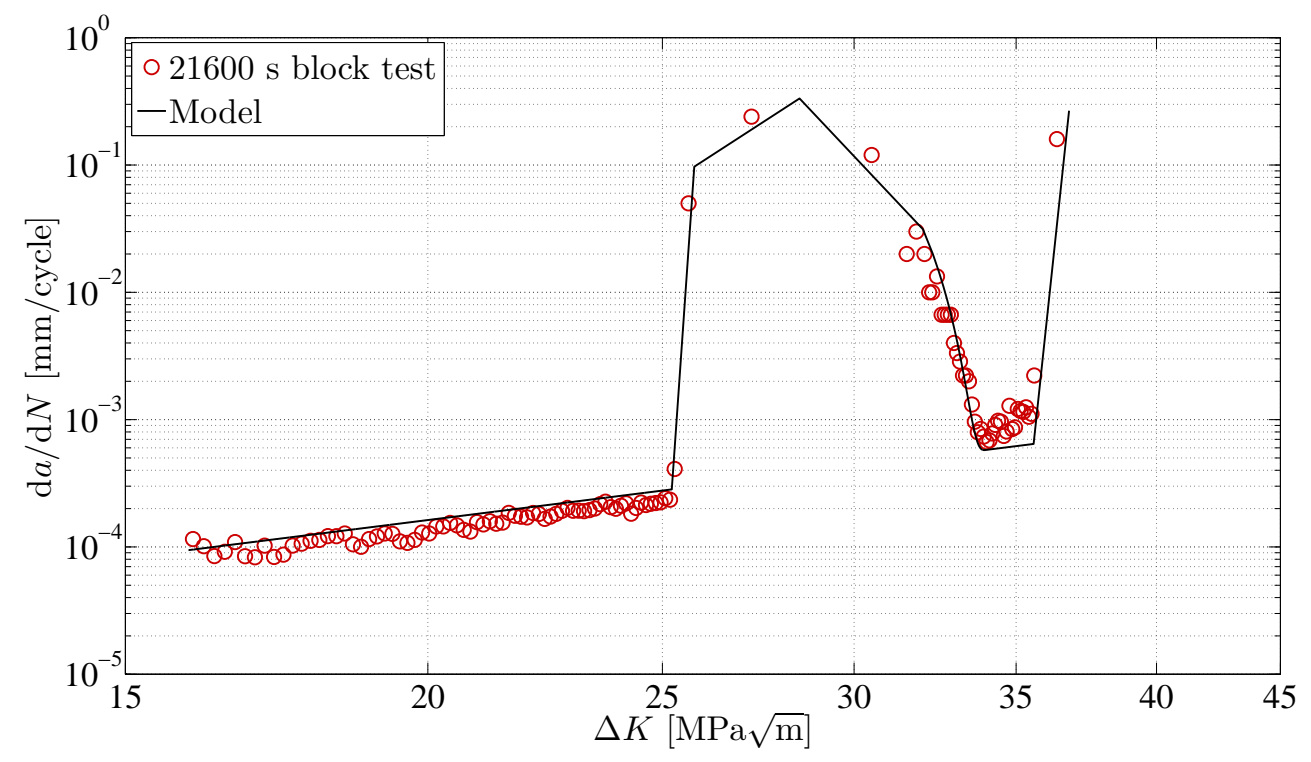

Figure 11: Model vs 21600 s block test

In Fig. 12 a comparison between block test results with $90 \mathrm{~s}$ hold time is shown. As can be seen, the model overpredicts the hold time parts. The reason for this is, most likely, that the $90 \mathrm{~s}$ hold time is too short to be in the fully time dependent region [13]. Since our modell does not consider effects specifically related to the region of mixed fracture, it fails to predict the correct crack growth rate for this short hold time. 


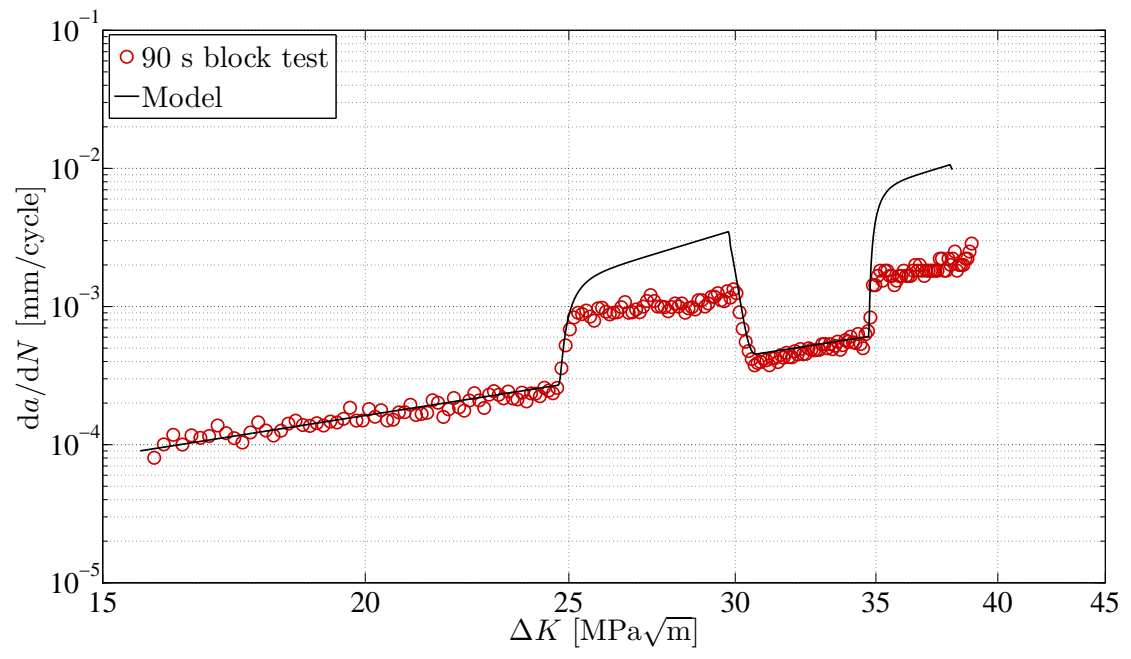

Figure 12: Model vs $90 \mathrm{~s}$ block test

In Fig. 13 the results for time dependent test with a long pre-crack of approximately $1.31 \mathrm{~mm}$ are shown. For comparison, the model output for the time dependent crack growth test with shorter pre-crack, found in Section 4.2, is plotted as well. As can be seen, the model does capture the overall behaviour of the experiment, but the transient in the beginning of the test is overpredicted, indicating that the equations for $\dot{D}$ and/or $S_{t}$ may need more complex expressions with more parameters, in order to handle the nonlinearities found in different transients. 


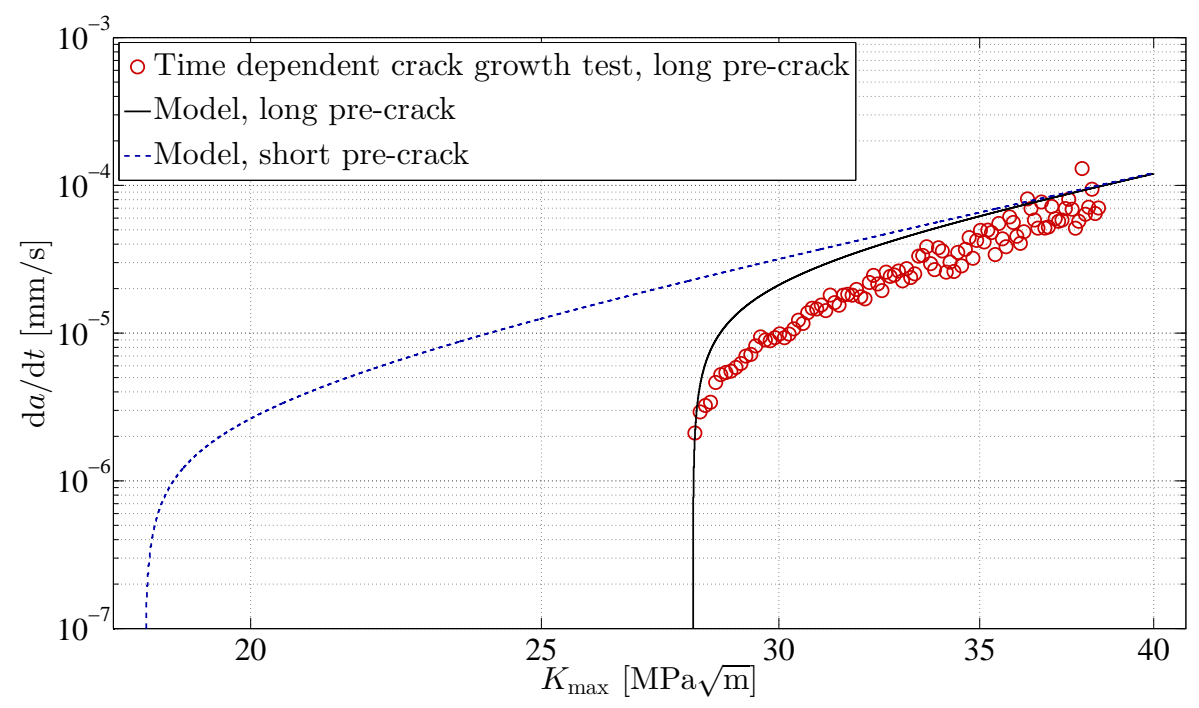

Figure 13: Model vs time dependent crack growth test with a long pre-crack. Also shown is the model output for the time dependent crack growth test found with shorter pre-crack

For typical results of the evolution of the damaged zone, see Fig. 14, where the damaged zone size for the $2160 \mathrm{~s}$ and the $21600 \mathrm{~s}$ block test is shown. First a cyclic crack growth block is applied and thus we see no growth of the damaged zone. After this a hold time block starts and we can now see a progressive build up of the damaged zone. It is to be noted that the saw tooth pattern appearing is due to the partial destruction of the damaged zone during each load reversal in between the hold times. After the hold time block another cyclic crack growth block begins. Here we see a progressive reduction of the zone until nothing remains. Finally, another hold time block starts and after a while the test finishes. As noted in Fig. 14, the two maximum values of the damaged zone are marked, and these are seen to be in good agreement with the ones measured in [21], $0.27 \mathrm{~mm}$ and $0.42 \mathrm{~mm}$ for the $2160 \mathrm{~s}$ and the $21600 \mathrm{~s}$ block test, respectively. 


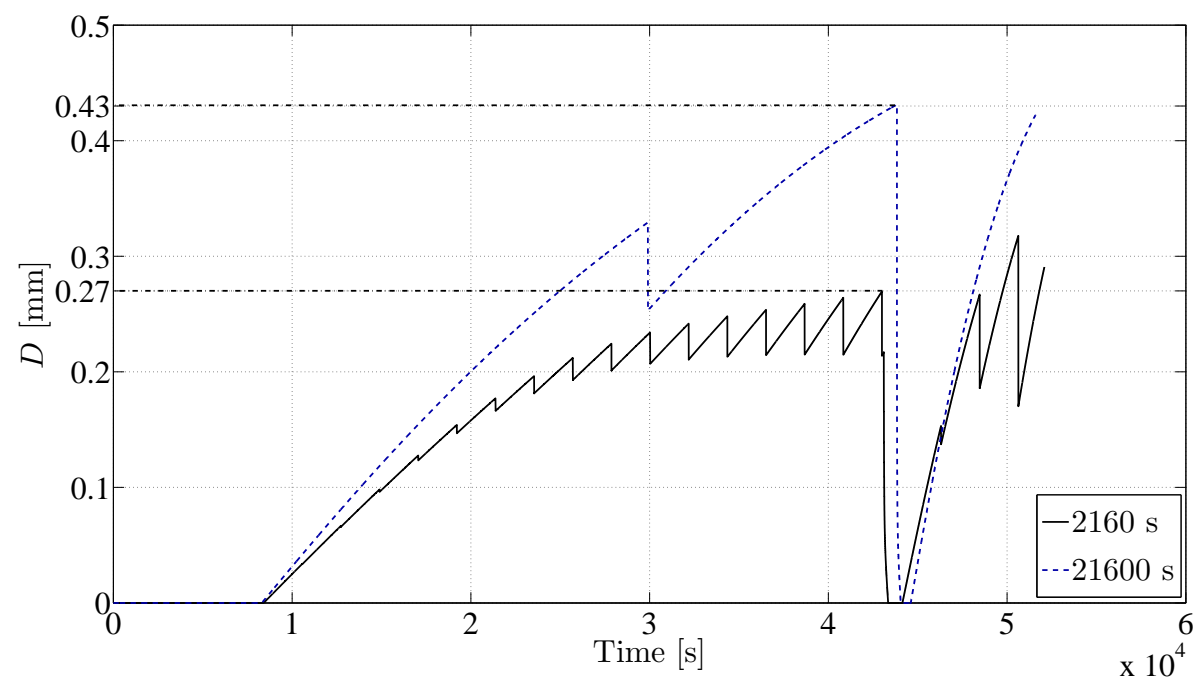

Figure 14: Build up and destruction of the damaged zone during the $2160 \mathrm{~s}$ and the $21600 \mathrm{~s}$ block test

\section{Summary and conclusions}

In this paper modelling of the hold time fatigue crack growth in Inconel 718 using the concept of a damaged zone as its basic foundation has been presented.

Using the evolution model of the damaged zone and the scale factors, hold time tests, time dependent crack growth tests and block tests can be handled satisfactorily. The model has few fitting parameters and the material parameters can easily be obtained from fatigue crack growth testing. However, the crack growth behaviour within the mixed transgranular/intergranular fracture region is not captured. Furthermore, only one temperature is considered. If the model were to be calibrated for higher temperatures, it would probably show a better agreement for shorter hold times since the time dependent region is growing with increasing temperature.

During the calibration procedure, different parts of the tests were used to cali- 
brate different parameters. This indicates that only one carefully planned test type needs to be used for determining all eight parameters (including $D_{\max }$ ) for one temperature. This can be done by first letting the test specimen be subjected to a constant loading i.e. a pure time dependent crack growth test which, when the Paris curve has been stabilised, is followed by a block of continuous cycling. From the transient which will be found during the cyclic block the stabilised damaged zone $\left(D_{\max }\right)$ will be found, see [6]. The rest of the parameters can then be obtained from well specified parts of the test, i.e. $B_{t}$ from the transient at the beginning, $C_{t}$ and $n_{t}$ from the stabilised part of the time dependent test, $A_{c}$ and $B_{c}$ from the transient during the start of the continuous cycling and finally $C_{c}$ and $n_{c}$ from the stabilised level at the final continuous cycling, for which the damaged zone has been completely consumed, see Fig. 15.

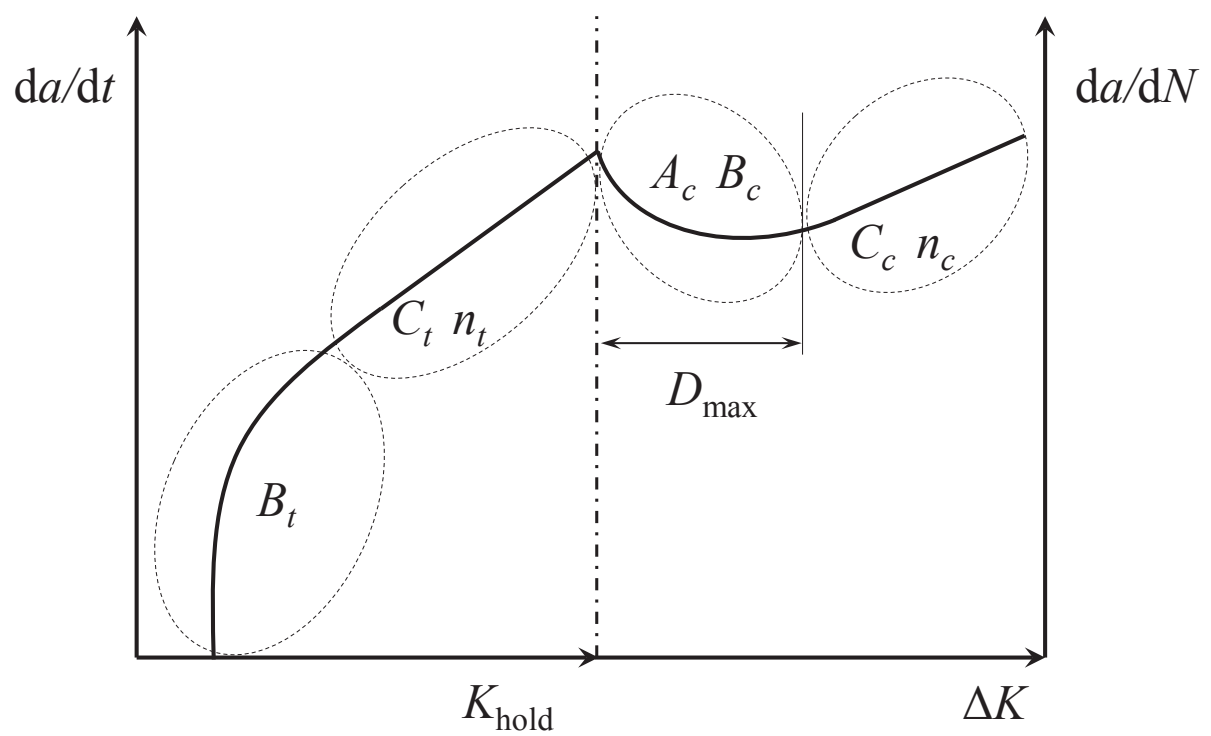

Figure 15: Proposed mechanical test for parameter determination

It should be pointed out that, at present we do not have access to a statistically relevant test population, only one experiment for each loading case, which of course will make the presented parameter determination only qualitative. 
Finally, this modelling paradigm should also be appropriate for including the effects of overloads. Such an addition may give a model able to predict many relevant component load cycles in a gas turbine context. Work concerning this is in progress.

\section{Acknowledgements}

The authors would like to thank Mr. Bo Skoog, Linköping University, for the laboratory work, and, further, the project teams at Linköping University, Siemens Industrial Turbomachinery AB and GKN Aerospace Engine Systems for valuable discussions. This research has been funded by the Swedish Energy Agency, Siemens Industrial Turbomachinery AB, GKN Aerospace Engine Systems, and the Royal Institute of Technology through the Swedish research program TURBO POWER, the support of which is gratefully acknowledged.

\section{References}

[1] R.C. Reed, The Superalloys - Fundamentals and Applications, Cambridge University Press, Cambridge, 2006.

[2] A. Pineau, S.D. Antolovich, High temperature of nickel-base superalloys A review with special emphasis on deformation modes and oxidation, Engineering Failure Analysis, 16 (2009) 2668-2697.

[3] D. Gustafsson, J.J. Moverare, S. Johansson, M. Hörnqvist, K. Simonsson, S. Sjöström, B. Sharifimajd, Fatigue crack growth behaviour of Inconel 718 with high temperature hold times, Procedia Engineering, 2(1) (2010) 1095-1104.

[4] P. Heuler, E. Affeldt, R.J.H. Wanhill, Effects of Loading Waveform and Stress Field on High Temperature Fatigue Crack Growth of Alloy 718, Materialwissenschaft und Werkstofftechnik, 34(9) (2003) 790-796. 
[5] J.P. Pédron, A. Pineau, The effect of microstructure and environment on the crack growth behaviour of Inconel 718 alloy at $650^{\circ} \mathrm{C}$ under fatigue, creep and combined loading, Materials Science and Engineering, 56(2) (1982) 143-156.

[6] D. Gustafsson, J.J. Moverare, S. Johansson, K. Simonsson, M. Hörnqvist, T. Månsson, S. Sjöström, Influence of high temperature hold times on the fatigue crack propagation in Inconel 718, International Journal of Fatigue, 33(11) (2011) 1461-1469.

[7] H. Ghonem, T. Nicholas, A. Pineau, Elevated Temperature Fatigue Crack Growth in Alloy 718-Part II: Effects of Environmental and Material Variables, Fatigue and Fracture of Engineering Materials and Structures, 16(6) (1993) 577-590.

[8] E. Andrieu, Intergranular crack tip oxidation mechanisms in nickel-based superalloy, Materials Science and Engineering 154(1) (1992) 21-8.

[9] R. Molins, G. Hochstetter, J.C. Chassaigne, E. Andrieu, Oxidation effects on the fatigue crack growth behavior of alloy 718 at high temperature, Acta Materialia, 45(2) (1997) 663-674.

[10] F.V. Antunes, High temperature fatigue crack growth in Inconel 718, Materials at High Temperatures, 17(4) (2000) 439-448.

[11] F. V. Antunes, J. M. Ferreira, C. M. Branco, J. Byrne, Influence of stress state on high temperature fatigue crack growth in Inconel 718, Journal of Materials Engineering and Performance, 24(2) (2008) 127-135.

[12] C.M. Branco, Fatigue behaviour of the nickel-based superalloy IN718 at elevated temperature, Materials at High Temperatures, 12(4) (1994) 261-267.

[13] T. Weerasooriya, Effect of Frequency on Fatigue Crack Growth Rate of Inconel 718 at High Temperature, Fracture Mechanics: 19th Symp. ASTM, 969 (1988) 907-923. 
[14] J. Gayda, T.P. Gabb, R.V. Miner, Fatigue crack propagation of nickelbase superalloys at $650^{\circ} \mathrm{C}$, American Society for Testing and Material, (1988) 293-309.

[15] A. Saxena, A model for predicting the effect of frequency on fatigue crack growth behaviour at elevated temperature, Fatigue and Fracture of Engineering Materials and Structures, 3(3) (1980) 247-255.

[16] A. Saxena, R.S. Williams, T.T. Shih, A model for representing and predicting the influence of hold time on Fatigue crack growth behaviour at elevated temperature, ASTM Special Technical Publication, (1981) 86-99.

[17] H. Ghonem, D. Zheng, Depth of intergranular oxygen diffusion during environment-dependent fatigue crack propagation in alloy 718, Materials Science and Engineering, 150 (1992) 151-160.

[18] R.H. Van Stone, D.C. Slavik, Prediction of Time Dependent Crack Growth with Retardation Effects in Nickel Base Alloys, ASTM STP 1389, (1999) $405-426$.

[19] D. Gustafsson, E. Lundström, High temperature fatigue crack growth behaviour of Inconel 718 under hold time and overload conditions, International Journal of Fatigue, 48 (2013) 178-186.

[20] K. Wackermann, U. Krupp, H-J. Christ, Effects of the Environment on the Crack Propagation Behavior of IN718 in the Temperature Range of the Dynamic Embrittlement, Journal of ASTM International, 8(5) (2011) 297312.

[21] D. Gustafsson, J.J. Moverare, K. Simonsson, S. Johansson, M. Hörnqvist, T. Månsson, S. Sjöström, Fatigue crack growth behaviour of Inconel 718 - The concept of a damaged zone caused by high temperature hold times, Procedia Engineering, 10 (2011) 2821-2826. 
[22] J.J. Moverare, D. Gustafsson, Hold-time effect on the thermo-mechanical fatigue crack growth behaviour of Inconel 718, Materials Science and Engineering A, 528(29-30) (2011) 8660-8670.

[23] P. Paris, F. Erdogan, A critical analysis of crack propagation laws, Journal of Basic Engineering, 85(4) (1963) 528-534.

[24] J.R. Haigh, R.P. Skelton, C.E. Richards, Oxidation-assisted crack growth during high cycle fatigue of a $1 \% \mathrm{Cr}-\mathrm{Mo}-\mathrm{V}$ steel at $550^{\circ} \mathrm{C}$, Materials Science and Engineering, 26(2) (1976) 167-174.

[25] H. Ghonem, D. Zheng, Oxidation-assisted fatigue crack growth behavior in alloy 718-part I. quantitative modeling, Fatigue \& Fracture of Engineering Materials \& Structures, 14(7) (1991) 749-760.

[26] R.P. Skelton, J.I. Bucklow, Cyclic oxidation and crack growth during high strain fatigue of low alloy steel, Metal Science, 12(2) (1978) 64-70.

[27] J.J. McGowan, H.W. Liu, A kinetic model of high temperature fatigue crack growth, Environment and temperature effects, (1983) 377-390.

[28] S. Krush, P. Prigent, J.L. Chaboche, A fracture mechanics based fatiguecreep-environment crack growth model for high temperature, International Journal of Pressure Vessels and Piping, 59 (1994) 141-148.

[29] F. Gallerneau, S. Kruch, P. Kanouté, A New Modelling of Crack Propagation with Fatigue-Creep-Oxidation Interaction under Non Isothermal Loading, Symposium on Ageing Mechanisms and Control: Part B Monitoring and Management of Gas Turbine Fleets for Extended Life and Reduced Costs, Mancherster UK, 8-11 October 2001.

[30] L.G. Zhao, J. Tong, M.C. Hardy, Prediction of crack growth in a nickelbased superalloy under fatigue-oxidation conditions, Engineering fracture mechanics, 77 (2010) 925-938. 
[31] K.O. Findley, J.L. Evans, A. Saxena, A critical assessment of fatigue crack nucleation and growth models for $\mathrm{Ni}$ - and $\mathrm{Ni}$, Fe-based superalloys, International Materials Reviews, 56(1) (2005) 49-71.

[32] J.M. Larsen and T. Nicholas, Load sequence crack growth transients in a superalloy at elevated temperature, Fracture Mechanics: Fourteenth Symposium - Volume II: Testing and Applications, ASTM STP 791, (1983) 536-552.

[33] T. Nicholas, T. Weerasooriya, Hold-time effects in elevated temperature fatigue crack propagation, Fracture Mechanics: Seventeenth Volume, ASTM STP 905, (1986) 155-168.

[34] L. Ma, K.-M.Chang, Identification of SAGBO-induced damage zone ahead of crack tip to characterize sustained loading crack growth in alloy 783 , Scripta Materialia, 48(9) (2003) 1271-1276.

[35] U. Krupp, Dynamic embrittlement - time-dependent quasi-brittle intergranular fracture at high temperatures, International Materials Reviews, 50 (2005) 83-97.

[36] U. Krupp, W. Kane, X. Liu, O. Dueber, C. Laird, C.J. McMahon Jr., The effect of grain-boundary-engineering-type processing on oxygen induced cracking of IN718, Materials Science and Engineering A, 349(1-2) (2002) 213217.

[37] D.A. Woodford, Gas phase embrittlement and time dependent cracking of Nickel based superalloys, Energy Materials, 1 (2006) 59-79.

[38] J.A. Pfaendtner, C.J. Jr McMahon, Oxygen-induced intergranular cracking of a Ni-based alloy at elevated temperatures - an example of dynamic embrittlement, Acta Materialia, 49 (2001) 3369-3377.

[39] D. Bika, J.A. Pfaendtner, M. Menyhard, C.J. Jr McMahon, Sulfur-induced dynamic embrittlement in a low-alloy steel, Acta Metallurgica et Materialia, 43(5) (1995) 1895-1908. 
[40] X.B. Liu, L.Z. Ma, K.M. Chang, E. Barbero, Fatigue Crack Propagation of Ni-based Superalloys, Acta Metallurgica Sinica, 18(1) (2005) 55-64.

[41] ASME E647-08., Standard test method for measurement of fatigue crack growth rates, Annual Book of ASME Standards, Volume 03.01, West Conshohocken (PA): ASM International.

[42] ASTM E740-03., Standard practice for fracture testing with surface-crack tension specimens, Annual Book of ASME Standards, Volume 03.01, West Conshohocken (PA): ASM International.

[43] U. Krupp, C.J. McMahon Jr, Dynamic embrittlement-time-dependent brittle fracture, Journal of Alloys and Compounds, 378 (2004) 79-84.

[44] MATLAB version 7.14.0.739 (R2012a), The MathWorks Inc., Natick, Massachusetts, (2012).

[45] N. Stander, W. Roux, T. Goel, T. Eggleston, K. Craig, LS-OPT User's manual, Version 4.2, Livermore Software Technology Corporation, Livermore, CA (2011). 